\title{
Safety and efficacy of S-1 monotherapy in elderly patients with advanced gastric cancer
}

\author{
Takahiro Tsushima ${ }^{1}$, Shuichi Hironaka ${ }^{1,2}$, Narikazu Boku ${ }^{1}$, Nozomu Machida ${ }^{1}$, Kentaro $_{\text {Yamazaki }}{ }^{1}$, \\ Hirofumi Yasui $^{1}$, Keisei Taku ${ }^{1}$, Akira Fukutomi ${ }^{1}$, and Yusuke Onozawa ${ }^{1}$ \\ ${ }^{1}$ Division of Gastrointestinal Oncology, Shizuoka Cancer Center, 1007 Shimonagakubo, Nagaizumi-cho, Shizuoka 411-8777, Japan \\ ${ }^{2}$ Clinical Research Promotion Department, Chiba Cancer Center, Chiba, Japan
}

\begin{abstract}
Background. Although S-1 is effective against advanced gastric cancer (AGC), its efficacy in elderly patients has not yet been investigated sufficiently. We assessed the efficacy and safety of S-1 monotherapy in elderly patients with AGC.

Methods. We conducted a retrospective review of the data of 153 patients with unresectable/recurrent gastric adenocarcinoma who received $\mathrm{S}-1$ monotherapy as first-line chemotherapy at our institution. S-1 was administered orally twice daily at the dose of $40 \mathrm{mg} / \mathrm{m}^{2}$, on days 1-28, every 6 weeks. We categorized the patients into three groups, the young $(\leq 65$ years old), the middle-aged (66-75 years old), and the elderly ( $\geq 76$ years old); and the drug toxicity, objective responses, progression-free survivals, and overall survivals were compared among the three groups.

Results. The incidence of leukopenia of grade 3 or greater in the three groups was $7 \%, 5 \%$, and $13 \%$, and that of anemia was $9 \%$, $18 \%$, and $27 \%$, respectively. In regard to nonhematological toxicities, the incidence of nausea of grade 3 or greater was $3 \%, 5 \%$, and $13 \%$; that of fatigue was $5 \%, 11 \%$, and $20 \%$; and that of anorexia was $5 \%, 6 \%$, and $27 \%$, respectively. As for the treatment efficacy, the objective response rates, median progressionfree survivals, and overall survivals in the young, middle-aged, and elderly groups were $53 \%, 46 \%$, and $33 \% ; 7.8,5.6$, and 3.9 months; and 16.9, 17.1; and 7.7 months, respectively.

Conclusion. Although S-1 monotherapy showed moderate efficacy in elderly ( $\geq 76$ years) patients with AGC, patients in this age group showed higher incidences of severe toxicities than the younger patients.
\end{abstract}

Key words S- $1 \cdot$ Elderly $\cdot$ Gastric Cancer $\cdot$ Safety $\cdot$ Efficacy

\section{Introduction}

Gastric cancer is the second leading cause of death from malignant disease in the world $[1,2]$. In Japan, gastric

Offprint requests to: $\mathrm{T}$. Tsushima

Received: April 8, 2010 / Accepted: July 6, 2010 cancer is the most frequently encountered malignancy and the second leading cause of cancer-related death [3]. The prognosis of unresectable or recurrent tumors is very poor: the median survival time is about 4 months with best supportive care [4-6]. Although several randomized trials of treatments for advanced gastric cancer were conducted during the 1990s, with anthracyclines, mitomycin C, 5-fluorouracil (5-FU), methotrexate, and cisplatin [7-15], no standard treatment for advanced gastric cancer was established.

S-1 is an oral fluoropyrimidine, consisting of tegafur (a prodrug of fluorouracil), 5-chloro-2, 4dihydropyrimidine (CDHP), and potassium oxonate. CDHP is an inhibitor of dihydropyrimidine dehydrogenase (DPD), which is the rate-limiting enzyme for the degradation of fluorouracil [16]. Three randomized controlled trials of S-1 monotherapy have been reported from Japan. One was the Japan Clinical Oncology Group (JCOG) 9912 trial, which showed the noninferiority of S-1 to continuous infusion of 5-FU, adopted as the reference arm for patients with unresectable or recurrent gastric cancer, based on the result of the JCOG9205 trial $[15,17]$. The second trial was the S-1 plus cisplatin versus S-1 in RCT in the treatment for stomach cancer (SPIRITS) trial, conducted in 2007, which showed the superiority of S-1 plus cisplatin to S-1 alone in patients with advanced gastric cancer [18]. The third trial was the randomized phase III study of irinotecan plus S-1 (IRIS) versus S-1 alone as first-line treatment for advanced gastric cancer (GC0301/TOP-002), which did not demonstrate the superiority of S-1 plus irinotecan (CPT-11) to S-1 alone [19]. From the results of these three phase III trials, S-1 plus cisplatin came to be recognized as the standard of care for patients with advanced gastric cancer in Japan, while S-1 monotherapy was a community standard until 2007.

In recent years, the percentage of elderly people in the general population in Japan has increased remarkably, to more than $20 \%$, owing to the prolonged lifespan of the 
Japanese. Considering this social background, chemotherapy for elderly cancer patients is an important issue that must be addressed. However, because gastric cancer patients who were more than 75 years old were not included in the three aforementioned Japanese phase III trials, elderly patients are generally administered monotherapy with $\mathrm{S}-1$, which is not as intensive as $\mathrm{S}-1$ plus cisplatin. However, the efficacy and toxicity of S-1 monotherapy in elderly patients has not yet been clarified.

In this study, we assessed the safety and efficacy of S-1 monotherapy as a function of the age of patients with advanced gastric cancer.

\section{Subjects, materials, and methods}

\section{Patients}

The subjects were patients with unresectable or recurrent gastric cancer who received S-1 monotherapy at our hospital. The patient selection criteria were as follows: Eastern Cooperative Oncology Group (ECOG) performance status (PS) 0-2; histologically proven adenocarcinoma; no previous history of chemotherapy; adequate oral intake; adequate bone marrow, renal, and hepatic functions (defined as an absolute neutrophil count of $\geq 1500 / \mu \mathrm{l}$, hemoglobin of $\geq 8.0 \mathrm{~g} / \mathrm{dl}$, serum creatinine of $\leq 1.5 \mathrm{mg} / \mathrm{dl}$, serum transaminase levels less than threefold the upper limit of normal); and no concomitant malignancy. The presence of measurable lesions was not mandatory.

We categorized the patients into three groups, as follows; the young group (less than 66 years old), the middle-aged group (66 years or older, but not older than 75 years), and the elderly (more than 75 years old).

\section{Treatment dose and schedule}

S-1 was administered orally twice daily at the dose of $40 \mathrm{mg} / \mathrm{m}^{2}$ from day 1 to day 28 , followed by 14 days' rest, and this regimen was repeated every 42 days until disease progression, the appearance of unacceptable toxicities, or the patient's refusal to continue treatment. The dosage of S-1 was determined according to the body surface area (BSA), as follows: BSA less than $1.25 \mathrm{~m}^{2}, 40 \mathrm{mg}$ bid; BSA 1.25 to $1.5 \mathrm{~m}^{2}, 50 \mathrm{mg}$ bid; BSA more than $1.5 \mathrm{~m}^{2}, 60 \mathrm{mg}$ bid. We suspended treatment during the cycle or delayed the treatment cycle until nonhematological toxicities recovered to grade 1 or lower, the neutrophil count was $1500 / \mu 1$, and the platelet count was $7.5 \times 10^{4} / \mu 1$. The dose of S-1 was reduced by $20 \%$ (level 1) in the event of any of the following occurrences during the previous cycle: grade 4 decrease in the leukocyte count, hemoglobin, or platelet count; and/or grade 3 or higher nonhematological toxicities. If these toxicities appeared again at the reduced dose, an additional reduction of the dose of S-1 by $20 \%$ (level 2 ) was made. The treatment schedule of 2 weeks' administration every 3 weeks was permitted if severe adverse events were seen after the second week in each course. A dose reduction of S-1 by one level at the initiation of the therapy was also permitted considering the patient's age, PS, and organ functions.

\section{Response and toxicity evaluation}

We obtained all the clinical data from the medical records retrospectively. We repeated physical examinations and laboratory tests at least once every 2 weeks. Objective response was assessed according to the Response Evaluation Criteria in Solid Tumors (RECIST), version 1.0, and toxicity was evaluated based on the National Cancer Institute Common Terminology Criteria for Adverse Events (CTCAE), version 3.0.

\section{Statistical analysis}

Overall survival (OS) was defined as the period from the date of the first administration of S-1 to the date of death from any cause or the last date on which the patient was confirmed to be alive. Progression-free survival (PFS) was defined as the period from the date of the first administration of S-1 to the date of confirmation of tumor progression by imaging, or the date of symptomatic deterioration by clinical judgment, or the last date on which the patient was confirmed to be alive without disease progression. Patients who had only the one noncurative factor of positive peritoneal washing cytology were excluded from the PFS and OS analyses, because it was suggested that these patients would survive longer than patients with other noncurative factors; however these patients' toxicities were assessed. Patients who did not have target lesions were also excluded from the response rate (RR) analysis. The survival curves were calculated by the Kaplan-Meier method, using StatView, version 5.0 (Abacus Concepts, Berkeley, CA, USA). Written informed consent was obtained from each of the patients prior to their starting the chemotherapy.

\section{Results}

\section{Patient characteristics}

A total of 165 patients received S-1 monotherapy between September 2002 and October 2007. Of these, 12 patients were excluded, for the following reasons: hepatic function disorder (5 patients), concomitant malignancy (3 patients), severe anemia (2 patients), renal failure (1 patient), and massive pleural effusion and/or ascites (1 patient). 
Table 1. Patient characteristics at baseline

\begin{tabular}{|c|c|c|c|c|c|}
\hline & & $\begin{array}{l}\text { Young } \\
(n=76)\end{array}$ & $\begin{array}{l}\text { Middle-aged } \\
\quad(n=62)\end{array}$ & $\begin{array}{l}\text { Elderly } \\
(n=15)\end{array}$ & $P$ value \\
\hline Age (years) & $\begin{array}{l}\text { Median } \\
\text { (range) }\end{array}$ & $\begin{array}{c}59.5 \\
(34-65)\end{array}$ & $\begin{array}{c}70 \\
(66-75)\end{array}$ & $\begin{array}{c}77 \\
(76-80)\end{array}$ & $<0.0001$ \\
\hline Sex & Male & 52 & 49 & 10 & 0.33 \\
\hline & Female & 24 & 13 & 5 & \\
\hline PS & $\begin{array}{l}0 \\
1 \\
2\end{array}$ & $\begin{array}{r}43 \\
32 \\
1\end{array}$ & $\begin{array}{r}26 \\
35 \\
1\end{array}$ & $\begin{array}{l}4 \\
8 \\
3\end{array}$ & 0.02 \\
\hline Tumor status & $\begin{array}{l}\text { Unresectable } \\
\text { Recurrent }\end{array}$ & $\begin{array}{l}59 \\
17\end{array}$ & $\begin{array}{r}54 \\
8\end{array}$ & $\begin{array}{r}14 \\
1\end{array}$ & 0.18 \\
\hline $\mathrm{CCr}(\mathrm{ml} / \mathrm{min})^{\mathrm{a}}$ & $\begin{array}{l}\text { Median } \\
\text { (range) }\end{array}$ & $\begin{array}{c}88.3 \\
(35.5-143.7)\end{array}$ & $\begin{array}{c}65.4 \\
(35.9-104.9)\end{array}$ & $\begin{array}{c}59.9 \\
(41.3-93.9)\end{array}$ & $<0.0001$ \\
\hline Macroscopic type & $\begin{array}{l}1 \\
2 \\
3 \\
4 \\
\text { Unknown }\end{array}$ & $\begin{array}{r}0 \\
19 \\
35 \\
20 \\
2\end{array}$ & $\begin{array}{r}2 \\
16 \\
32 \\
9 \\
3\end{array}$ & $\begin{array}{l}2 \\
7 \\
2 \\
4 \\
0\end{array}$ & 0.16 \\
\hline Histological type & $\begin{array}{l}\text { Intestinal } \\
\text { Diffuse } \\
\text { Unknown }\end{array}$ & $\begin{array}{r}15 \\
60 \\
1\end{array}$ & $\begin{array}{r}26 \\
32 \\
4\end{array}$ & $\begin{array}{l}8 \\
7 \\
0\end{array}$ & 0.01 \\
\hline No. of metastatic sites & $\begin{array}{l}1 \\
2 \\
\geq 3\end{array}$ & $\begin{array}{r}54 \\
18 \\
4\end{array}$ & $\begin{array}{r}28 \\
31 \\
3\end{array}$ & $\begin{array}{l}5 \\
7 \\
3\end{array}$ & 0.003 \\
\hline Target lesions & $\begin{array}{l}+ \\
-\end{array}$ & $\begin{array}{l}32 \\
44\end{array}$ & $\begin{array}{l}35 \\
27\end{array}$ & $\begin{array}{r}12 \\
3\end{array}$ & 0.02 \\
\hline Noncurative factors & $\begin{array}{l}\text { Only CY1 } \\
\text { Others }\end{array}$ & $\begin{array}{l}20 \\
56\end{array}$ & $\begin{array}{l}12 \\
50\end{array}$ & $\begin{array}{r}1 \\
14\end{array}$ & 0.21 \\
\hline
\end{tabular}

The $P$ values were determined using the Kruskal-Wallis test

PS, performance status; $\mathrm{CCr}$, creatinine clearance; CY1, positive peritoneal washing cytology

${ }^{\text {a }}$ Cockcroft-Gault equation

The baseline characteristics of the patients in the three groups are shown in Table 1. The median age was 59.5 years (range, 34 to 65 years) in the young group, 70 years (range, 66 to 75 years) in the middle-aged group, and 77 years (range, 76 to 80 years) in the elderly group. The percentage of patients with PS 2 was higher $(20 \%)$ in the elderly group than in the other two groups. The median creatinine clearance (calculated by the Cockcroft-Gault equation) was $88.3 \mathrm{ml} / \mathrm{min}$ in the young group, $65.4 \mathrm{ml} / \mathrm{min}$ in the middle-aged group, and $59.9 \mathrm{ml} / \mathrm{min}$ in the elderly group. There were $32(42 \%)$, $35(56 \%)$, and $12(80 \%)$ patients with target lesions, and $20(26 \%), 12(19 \%)$, and $1(6 \%)$ patients with positive peritoneal washing cytology as the only noncurative factor in the young, middle-aged, and elderly groups, respectively.

\section{Exposure to treatment}

The median number of treatment cycles was 5.5 (range, 1 to 28 ) in the young group, 5 (range, 1 to 18) in the middle-aged group, and 3 (range, 1 to 13 ) in the elderly group. Dose reduction of S-1 was required in some patients in all three groups: in 12 patients $(16 \%)$ in the young group, 14 patients $(23 \%)$ in the middle-aged group, and 8 patients (53\%) in the elderly group. Delay of the subsequent treatment cycle was also necessitated in some patients in all three groups: in 23 patients $(30 \%)$ in the young group, 26 patients $(42 \%)$ in the middleaged group, and 5 patients $(33 \%)$ in the elderly group.

The median relative dose intensity (RDI) per patient in the elderly group was only $75.8 \%$, whereas the corresponding values in the young and middle-aged groups were $99.5 \%$ and $96.3 \%$. In $7(47 \%)$ of the 15 patients in the elderly group, S-1 was administered at a reduced dose from the start, and in 8 patients in the elderly group $(53 \%)$, the dose of S-1 was reduced due to the appearance of toxicity during the treatment courses, and 3 of these 8 patients needed additional dose reduction because of the development of severe adverse events.

The reasons for treatment discontinuation are shown in Table 2. The most frequent reason in all three groups was disease progression. While two patients in the young group required treatment discontinuation because of the development of adverse events (grade 3 pneumonitis in one, and grade 2 skin rash in the other), none of the patients in the elderly group required treatment 
Table 2. Reasons for treatment discontinuation

\begin{tabular}{lccc}
\hline & $\begin{array}{c}\text { Young } \\
(n=76)\end{array}$ & $\begin{array}{c}\text { Middle-aged } \\
(n=62)\end{array}$ & $\begin{array}{c}\text { Elderly } \\
(n=15)\end{array}$ \\
\hline S-1 discontinuation & $74(97 \%)$ & $62(100 \%)$ & $15(100 \%)$ \\
Disease progression & 60 & 52 & 13 \\
Adverse events & 2 & 0 & 0 \\
Patient's refusal & 0 & 3 & 0 \\
Lost to follow-up & 1 & 1 & 1 \\
\hline
\end{tabular}

Table 3. Adverse events

\begin{tabular}{|c|c|c|c|c|c|c|c|c|c|c|c|c|c|}
\hline & \multicolumn{4}{|c|}{$\begin{array}{l}\text { Young } \\
(n=76)\end{array}$} & \multicolumn{4}{|c|}{$\begin{array}{l}\text { Middle-aged } \\
\quad(n=62)\end{array}$} & \multicolumn{4}{|c|}{$\begin{array}{l}\text { Elderly } \\
(n=15)\end{array}$} & \multirow[b]{2}{*}{$P$ value } \\
\hline & $\mathrm{G} 1 / 2$ & G3 & G4 & $\geq \mathrm{G} 3(\%)$ & $\mathrm{G} 1 / 2$ & G3 & G4 & $\geq \mathrm{G} 3(\%)$ & $\mathrm{G} 1 / 2$ & G3 & $\mathrm{G} 4$ & $\geq \mathrm{G} 3(\%)$ & \\
\hline \multicolumn{14}{|l|}{ Hematological } \\
\hline Leukopenia & 41 & 5 & 0 & 7 & 36 & 3 & 0 & 5 & 3 & 2 & 0 & 13 & 0.28 \\
\hline Neutropenia & 26 & 10 & 1 & 14 & 25 & 5 & 0 & 8 & 2 & 2 & 0 & 13 & 0.45 \\
\hline Anemia & 63 & 7 & 0 & 9 & 51 & 10 & 1 & 18 & 9 & 4 & 0 & 27 & 0.08 \\
\hline Thrombocytopenia & 21 & 1 & 0 & 1 & 15 & 1 & 0 & 2 & 6 & 0 & 0 & 0 & 0.59 \\
\hline \multicolumn{14}{|l|}{ Nonhematological } \\
\hline Nausea & 28 & 2 & 0 & 3 & 16 & 3 & 0 & 5 & 7 & 2 & 0 & 13 & 0.08 \\
\hline Vomiting & 16 & 0 & 0 & 0 & 9 & 0 & 0 & 0 & 5 & 0 & 0 & 0 & 0.24 \\
\hline Anorexia & 40 & 4 & 0 & 5 & 34 & 4 & 0 & 6 & 8 & 4 & 0 & 27 & 0.07 \\
\hline Diarrhea & 29 & 0 & 0 & 0 & 16 & 0 & 0 & 0 & 5 & 0 & 0 & 0 & 0.31 \\
\hline Mucositis & 25 & 1 & 0 & 1 & 22 & 4 & 0 & 6 & 6 & 0 & 0 & 0 & 0.53 \\
\hline Fatigue & 19 & 4 & 0 & 5 & 21 & 7 & 0 & 11 & 8 & 3 & 0 & 20 & 0.004 \\
\hline Febrile neutropenia & - & 0 & 0 & 0 & - & 0 & 0 & 0 & - & 0 & 0 & 0 & \\
\hline Death within 30 days & & & & 0 & & & & 0 & & & & 1 & \\
\hline
\end{tabular}

The $P$ values were determined using the Kruskal-Wallis test

discontinuation because of adverse events or the patient's refusal.

\section{Adverse events}

Table 3 shows the adverse events until 30 days from the last administration of S-1 or the day of initiation of second-line treatment, whichever was earlier. The incidences of grade $3 / 4$ decreases in the leukocyte count and serum hemoglobin were $7 \%$ and $9 \%$ in the young group, $5 \%$ and $18 \%$ in the middle-aged group, and $13 \%$ and $27 \%$ in the elderly group, respectively. One patient in the middle-aged group showed a grade 4 decrease in serum hemoglobin, and one patient in the young group showed grade 4 neutropenia. In regard to the nonhematological toxicities, the incidences of grade 3/4 nausea, anorexia, and fatigue seemed to be higher in the elderly group than in the other two groups. Thus, it would appear that patients in the elderly group experienced more severe hematological and nonhematological toxicities than those in the young and middle-aged groups, while the incidences of toxicities were similar in the young and middle-aged groups. One patient in the elderly group died within 30 days from the last administration of S-1. He was 80 years old, with PS 2, and the estimated creatinine clearance was $56 \mathrm{ml} / \mathrm{min}$ at the baseline. He received S-1 administration at a reduced dose even from the first cycle because of his advanced age and anorexia caused by primary cancer. When he visited our hospital on day 17 , he was found to have grade 2 mucositis. On day 23, he was admitted to another hospital because of severe anorexia and fatigue, and received some infusion therapy. However, he died on day 30 after the last administration of S-1. The attending physician judged that the cause of death was disease progression.

\section{Response and survival}

Among the patients with target lesions, the RR was $53 \%(17 / 32)$ in the young group, $46 \%(16 / 35)$ in the middle-aged group, and $33 \%(4 / 12)$ in the elderly group. Two patients $(6 \%)$ in the middle-aged group showed a complete response (CR).

The data of 56 patients in the young group, 50 in the middle-aged group, and 14 in the elderly group were analyzed in the calculations of the PFS and OS. The median PFS values in the young group, middle-aged group, and elderly group were 7.8 months, 5.6 months, and 3.9 months (Fig. 1), and the median overall survivals 


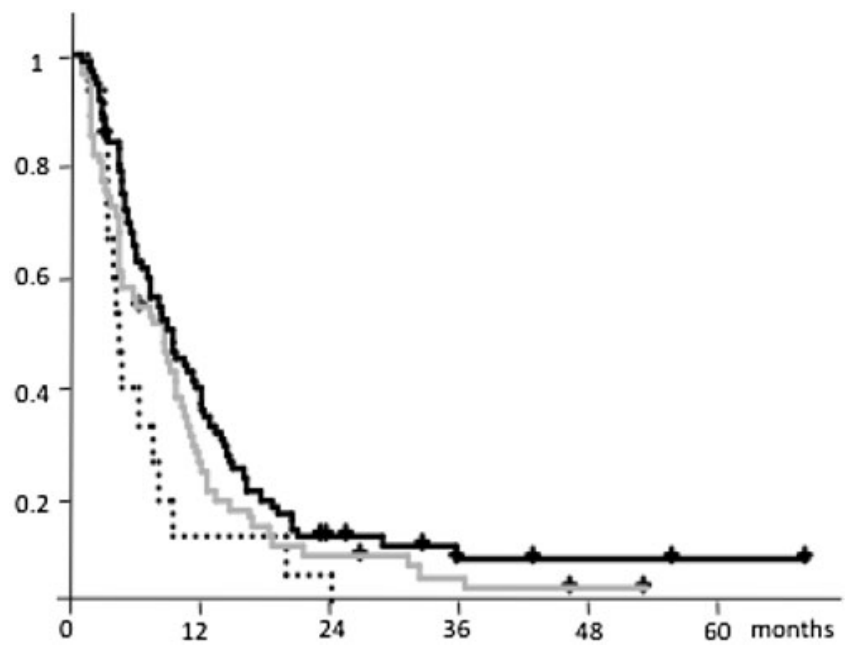

Fig. 1. The median progression-free survival (PFS) was 7.8 months in the young group (solid line), 5.6 months in the middle-aged group (faint line), and 3.9 months in the elderly group (dotted line)

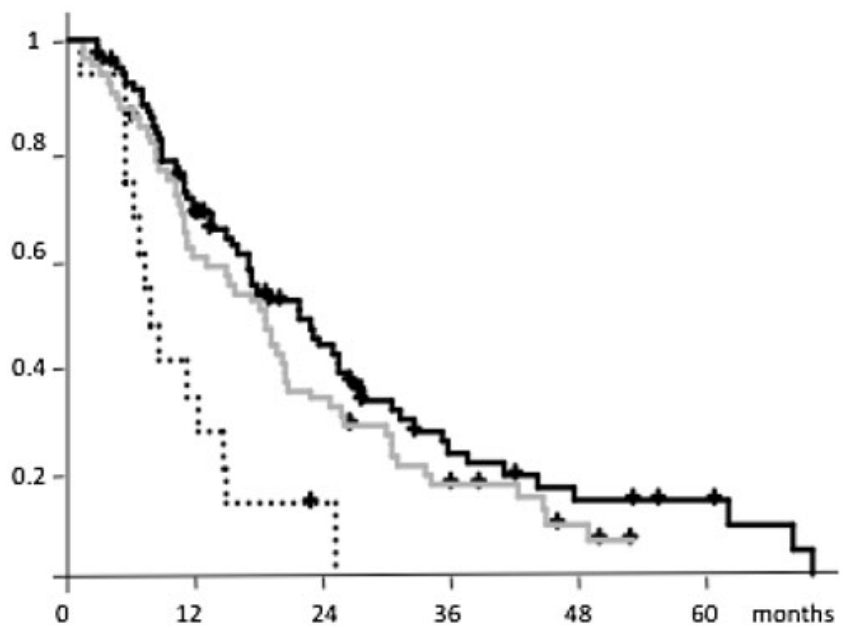

Fig. 2. The median OS was 16.9 months in the young group (solid line), 17.1 months in the middle-aged group (faint line), and 7.7 months in the elderly group (dotted line)

in the three groups were 16.9 months, 17.1 months, and 7.7 months, respectively (Fig. 2). It would seem that the treatment efficacy in the elderly group was inferior to that in the other two groups, while the young and middle-aged groups showed similar treatment efficacy.

\section{Discussion}

It still remains under debate whether standard chemotherapies established by pivotal phase III trials might also be applicable to elderly patients with advanced gastric cancer [20-23]. Lee et al. [24] conducted a ran- domized phase II study comparing capecitabine and S-1 in patients older than 65 years, and showed satisfactory efficacy of S-1 (RR, 29\%; median time to progression, 4.2 months; median OS, 8.1 months). In Japan, Koizumi et al. [25] conducted a phase II study of S-1 in patients older than 75 years and demonstrated a RR of $21 \%$, median PFS of 3.9 months, and median OS of 15.7 months. Similar results were obtained in the elderly group in the present study. Because these results are consistent with those of the previous phase III studies in Japan [17-19] (RR of about 30\% and PFS of about 4 months), it is considered that S-1 monotherapy may be effective in elderly patients with gastric cancer.

However, elderly cancer patients often have comorbidities and age-related physiological problems, such as organ dysfunction. The kidney is a very common route for the excretion of drugs; however, it is reported that the glomerular filtration rate generally decreases by approximately $0.75 \mathrm{ml} / \mathrm{min}$ per year after the age of 40 , on average [26]. In several pharmacokinetic studies of chemotherapeutic drugs, such as paclitaxel, vinorelbine, etoposide, cisplatin, and doxorubicin, an age-related decrease in creatinine clearance has been reported [23].

Lee et al. [24] and Koizumi et al. [25] reported the following incidences of grade $3 / 4$ toxicities: decrease in serum hemoglobin, 9\%-14.3\%; anorexia, 9.5\%-12\%; and nausea, $4.8 \%-6 \%$. These data are similar to those in the middle-aged group in the present study (decrease in serum hemoglobin, 18\%; anorexia, 6\%; nausea, $5 \%)$. In the elderly group in the present study, the incidences of severe toxicities (decrease in serum hemoglobin, 27\%; anorexia, 27\%; nausea, 13\%) were higher than those reported from the previous trials, despite about half of our elderly patients having received S-1 at a reduced dose from the first administration. The conditions of patients in daily clinical practice are generally worse than those in patients participating in clinical trials. Actually, in the present study, the median creatinine clearance, estimated by the Cockcroft-Gault equation, was lower in the elderly group $(59.9 \mathrm{ml} / \mathrm{min})$ than the values in the middle-aged $(65.4 \mathrm{ml} / \mathrm{min})$ and younger $(88.3 \mathrm{ml} / \mathrm{min})$ groups. It is known that the clearance of CDHP is reduced by renal dysfunction, resulting in a high blood concentration of 5-FU due to decreased DPD activity [27, 28]. In a post-marketing survey of S-1, it was reported that the incidence of toxicities was greater in patients with renal dysfunction than in those with normal renal function [29]. Thus, it is considered that renal dysfunction is the main reason for the high incidence of severe S-1 toxicities in elderly patients. Therefore, careful evaluation of the renal function prior to the initiation of S-1 monotherapy is strongly recommended.

In conclusion, in the present study, although S-1 monotherapy exhibited moderate efficacy in elderly 
patients ( $\geq 76$ years of age) with advanced gastric cancer, this subject population is at a higher risk of severe toxicities than the other two age groups (66-75 years old and younger) examined in this study. Careful monitoring of renal function and toxicities during treatment is recommended, especially in elderly patients.

\section{References}

1. Munoz N, Franceschi S. Epidemiology of gastric cancer and perspectives for prevention. Salud Publica Mex 1997;39:318-30.

2. Kamangar F, Dores GM, Anderson WF. Patterns of cancer incidence, mortality, and prevalence across five continents: defining priorities to reduce cancer disparities in different geographic regions of the world. J Clin Oncol 2006;24:2137-50.

3. Inoue M, Tsugane S. Epidemiology of gastric cancer in Japan. Postgrad Med J 2005;81:419-24.

4. Murad AM, Santiago FF, Petroianu A, Rocha PR, Rodrigues MA, Rausch M. Modified therapy with 5-fluorouracil, doxorubicin, and methotrexate in advanced gastric cancer. Cancer 1993;72:37-41.

5. Glimelius B, Hoffman K, Haglund U, Nyren O, Sjoden PO. Initial or delayed chemotherapy with best supportive care in advanced gastric cancer. Ann Oncol 1994;5:189-90.

6. Pyrhonen S, Kuitunen T, Nyandoto P, Kouri M. Randomised comparison of fluorouracil, epidoxorubicin and methotrexate (FEMTX) plus supportive care with supportive care alone in patients with non-resectable gastric cancer. Br J Cancer 1995; 71:587-91.

7. Cullinan SA, Moertel CG, Fleming TR, Rubin JR, Krook JE, Everson LK, et al. A comparison of three chemotherapeutic regimens in the treatment of advanced pancreatic and gastric carcinoma. Fluorouracil versus fluorouracil and doxorubicin versus fluorouracil, doxorubicin, and mitomycin. JAMA 1985;253: 2061-7.

8. Wils JA, Klein HO, Wagener DJ, Bleiberg H, Reis H, Korsten F, et al. Sequential high-dose methotrexate and fluorouracil combined with doxorubicin-a step ahead in the treatment of advanced gastric cancer: a trial of the European Organization for Research and Treatment of Cancer Gastrointestinal Tract Cooperative Group. J Clin Oncol 1991;9:827-31.

9. Kelsen D, Atiq OT, Saltz L, Niedzwiecki D, Ginn D, Chapman D, et al. FAMTX versus etoposide, doxorubicin, and cisplatin: a random assignment trial in gastric cancer. J Clin Oncol 1992; 10:541-8.

10. Cocconi G, Bella M, Zironi S, Algeri R, Di Costanzo F, De Lisi V, et al. Fluorouracil, doxorubicin, and mitomycin combination versus PELF chemotherapy in advanced gastric cancer: a prospective randomized trial of the Italian Oncology Group for Clinical Research. J Clin Oncol 1994;12:2687-93.

11. Webb A, Cunningham D, Scarffe JH, Harper P, Norman A, Joffe $\mathrm{JK}$, et al. Randomized trial comparing epirubicin, cisplatin, and fluorouracil versus fluorouracil, doxorubicin, and methotrexate in advanced esophagogastric cancer. J Clin Oncol 1997;15:2617.

12. Vanhoefer U, Rougier P, Wilke H, Ducreux MP, Lacave AJ, Van Cutsem E, et al. Final results of a randomized phase III trial of sequential high-dose methotrexate, fluorouracil, and doxorubicin versus etoposide, leucovorin, and fluorouracil versus infusional fluorouracil and cisplatin in advanced gastric cancer: a trial of the European Organization for Research and Treatment of Cancer Gastrointestinal Tract Cancer Cooperative Group. J Clin Oncol 2000;18:2648-57.
13. Kim NK, Park YS, Heo DS, Suh C, Kim SY, Park KC, et al. A phase III randomized study of 5-fluorouracil and cisplatin versus 5-fluorouracil, doxorubicin, and mitomycin $\mathrm{C}$ versus 5-fluorouracil alone in the treatment of advanced gastric cancer. Cancer 1993;71:3813-8.

14. Cullinan SA, Moertel CG, Wieand HS, O’Connel MJ, Poon MA, Krook JE, et al. Controlled evaluation of three drug combination regimen versus fluorouracil alone in the therapy of advanced gastric cancer. J Clin Oncol 1994;12:412-6.

15. Ohtsu A, Shimada Y, Shirao K, Boku N, Hyodo I, Saito H, et al. Randomized phase III trial of fluorouracil alone versus fluorouracil plus cisplatin versus uracil and tegafur plus mitomycin in patients with unresectable, advanced gastric cancer: The Japan Clinical Oncology Group Study (JCOG9205). J Clin Oncol 2003;21:54-9.

16. Shirasaka T, Shimamoto Y, Ohshimo H, Yamaguchi M, Kato T, Yonekura K, et al. Development of a novel form of an oral 5 -fluorouracil derivative (S-1) directed to the potentiation of the tumor selective cytotoxicity of 5-fluorouracil by two biochemical modulators. Anticancer Drugs 1996;7:548-57.

17. Boku N, Yamamoto S, Fukuda H, Shirao K, Doi T, Sawaki A, et al. Fluorouracil versus combination of irinotecan plus cisplatin versus S-1 in metastatic gastric cancer: a randomised phase 3 study. Lancet Oncol 2009;10:1063-9.

18. Koizumi W, Narahara H, Hara T, Takagane A, Akiya T, Takagi M, et al. S-1 plus cisplatin versus S-1 alone for first-line treatment of advanced gastric cancer (SPIRITS trial): a phase III trial. Lancet Oncol 2007;9:215-21.

19. Imamura $H$, Ishii $H$, Tsuburaya $A$, Hatake $K$, Imamoto $H$, Esaki $\mathrm{T}$, et al. Randomized phase III study of irinotecan plus S-1 (IRIS) versus $\mathrm{S}-1$ alone as first-line treatment for advanced gastric cancer (GC 0301/TOP-002). ASCO-GI 2008;Abstract no. 5.

20. Lichtman SM, Wildiers H, Chatelut E, Steer C, Budman D, Morrison VA, et al. International Society Of Geriatric Oncology Chemotherapy Taskforce: evaluation of chemotherapy in older patients - an analysis of the medical literature. J Clin Oncol 2007;25:1832-43.

21. Repetto L, Balducci L. A case of geriatric oncology. Lancet Oncol 2002;3:289-97.

22. Lichtman SM, Boparai MK. Anticancer drug therapy in the older cancer patient: pharmacology and polypharmacy. Curr Treat Options Oncol 2008;9:191-203.

23. Hurria A, Lichtman SM. Clinical pharmacology of cancer therapies in older adults. Br J Cancer 2008;98:517-22.

24. Lee JL, Kang YK, Kang HJ, Lee KH, Zang DY, Ryoo BY, et al. A randomised multicentre phase II trial of capecitabine vs S-1 as first-line treatment in elderly patients with metastatic or recurrent unresectable gastric cancer. Br J Cancer 2008;99:584-90.

25. Koizumi W, Akiya T, Sato A, Sakuyama T, Sasaki E, Tomidokoro T, et al. Phase II study of S-1 as first-line treatment for elderly patients over 75 years of age with advanced gastric cancer: the Tokyo Cooperative Oncology Group Study. Cancer Chemother Pharmacol 2010;65:1093-9.

26. Lindeman RD, Tobin J, Shock NW. Longitudinal studies of decline in renal function with age. J Am Geriatr Soc 1985;33:278-85.

27. Tatsumi K, Fukushima M, Shirasaka T, Fujii S. Inhibitory effects of pyrimidine, barbituric acid and pyridine derivatives on 5 -fluorouracil degradation in rat liver extracts. Jpn J Cancer Res 1987;78:748-55.

28. Hirata K, Horikoshi N, Aiba K, Okazaki M, Denno R, Sasaki K, et al. Pharmacokinetic study of S-1, a novel oral fluorouracil antitumor drug. Clin Cancer Res 1999;5:2000-5.

29. Nagashima F, Ohtsu A, Yoshida S, Ito K. Japanese nationwide post-marketing survey of S-1 in patients with advanced gastric cancer. Gastric Cancer 2005;8:6-11. 